\title{
A NOTE ON A GENERALIZATION OF INJECTIVE MODULES
}

\author{
TÜRKMEN B.N., TÜRKMEN E.
}

\begin{abstract}
As a proper generalization of injective modules in term of supplements, we say that a module $M$ has the property (ME) if, whenever $M \subseteq N, M$ has a supplement $K$ in $N$, where $K$ has a mutual supplement in $N$. In this study, we obtain that (1) a semisimple $R$-module $M$ has the property (E) if and only if $M$ has the property (ME); (2) a semisimple left $R$-module $M$ over a commutative Noetherian ring $R$ has the property (ME) if and only if $M$ is algebraically compact if and only if almost all isotopic components of $M$ are zero; (3) a module $M$ over a von Neumann regular ring has the property (ME) if and only if it is injective; (4) a principal ideal domain $R$ is left perfect if every free left $R$-module has the property (ME)

Key words and phrases: supplement, mutual supplement, module with the property (ME), left perfect ring.
\end{abstract}

Faculty of Science and Literature, Amasya University, 16160, Amasya, Turkey

E-mail: burcunisancie@hotmail.com (Türkmen B.N.), ergulturkmen@hotmail.com (Türkmen E.)

\section{INTRODUCTION}

In this paper, all rings are associative with identity and all modules are unital left modules. Let $R$ be such a ring and let $M$ be an $R$-module. The notation $K \subseteq M(K \subset M)$ means that $K$ is a (proper) submodule of $M$. A non-zero submodule $K \subseteq M$ is called essential in $M$, written as $K \unlhd M$, if $K \cap L \neq 0$ for every non-zero submodule of $M$. Dually, a proper submodule $S \subset M$ is called small (in $M$ ), denoted by $S \ll M$, if $M \neq S+K$ for every proper submodule $K$ of $M$. A module $M$ is called hollow if every submodule of $M$ is small in $M$. By $\operatorname{Rad}(M)$, namely radical, we will denote the sum of all small submodules of $M$. Equivalently, $\operatorname{Rad}(M)$ is the intersection of all maximal submodules of $M$ [9]. Following [9], a module $M$ is called supplemented if every submodule of $M$ has a supplement in $M$. A submodule $K \subseteq M$ is a supplement of a submodule $L$ in $M$ if and only if $M=L+K$ and $L \cap K \ll K$.

In [1], a supplement submodule $X$ of $M$ is then defined when $X$ is a supplement of some submodule of $M$. Every direct summand of a module $M$ is a supplement submodule of $M$, and supplemented modules are a generalization of semisimple modules. In addition, every factor module of a supplemented module is again supplemented. A module $M$ is called $\oplus$-supplemented if every submodule $N$ of $M$ has a supplement that is a direct summand of $M$ [5]. Clearly every $\oplus$-supplemented module is supplemented, but a supplemented module need not be $\oplus$-supplemented in general (see [5, Lemma A.4 (2)]). It is shown in [5, Proposition A.7 and Proposition A.8] that if $R$ is a Dedekind domain, every supplemented $R$-module is $\oplus$-supplemented. Hollow modules are $\oplus$-supplemented.

$\overline{\mathrm{y} \Delta \mathrm{K} 512.552}$

2010 Mathematics Subject Classification: 16D10,16D50,16N80. 
Let $M$ be a module. A module $N$ is said to be extension of $M$ provided $M \subseteq N$. As a generalization of injective modules, since every direct summand is a supplement, Zöschinger defined in [10] a module $M$ with the property $(E)$ if it has a supplement in every extension. He studied the various properties of a module $M$ with the property (E) in the same paper. For a module $N$, two submodules $K$ and $K^{\prime}$ of $N$ are called mutual supplements if $N=K+K^{\prime}$, $K \cap K^{\prime} \ll K$ and $K \cap K^{\prime} \ll K^{\prime}$. We consider the following condition for a module $M$ :

(ME) in any extension $N$ of $M, M$ has a supplement $K$ in $N$ and there exists a submodule $K^{\prime}$ of $N$ such that $K$ and $K^{\prime}$ are mutual supplements in $N$.

Now we have these implications on modules:

$$
\text { injective } \Rightarrow \text { module with the property }(M E) \Rightarrow \text { module with the property }(E) \text {. }
$$

Some examples are given to show that these inclusions are proper. In the section 2, we obtain some elementary facts about the property (ME). We prove that a semisimple $R$-module $M$ has the property (E) if and only if $M$ has the property (ME). We also prove that $M$ has the property (ME) if and only if $M$ is algebraically compact if and only if almost all isotopic components of $M$ are zero for a semisimple left $R$-module $M$ over a commutative Noetherian ring $R$. We obtain that a module $M$ over a von Neumann regular ring has the property (ME) if and only if it is injective. We show that any factor module of a module with the property (ME) doesn't have the property (ME). Finally, we also show that $R$ is left perfect if every free left $R$-module has the property (ME) over a principal ideal domain $R$.

\section{MOdUles With THE PROPERTY (ME)}

Proposition 1. Let $M$ be a semisimple $R$-module. Then, the following statements are equivalent.

(1) $M$ has the property (E).

(2) $M$ has the property (ME).

Proof. (1) $\Longrightarrow(2)$ Let $N$ be any extension of $M$. By (1), we have $N=M+K$ and $M \cap K \ll K$ for some submodule $K \subseteq M$. Since $M$ is a semisimple module, there exists a submodule $X$ of $M$ such that $M=(M \cap K) \oplus X$. So $(M \cap K) \cap X=K \cap X=0$. Therefore $N=M+K=$ $[(M \cap K) \oplus X]+K=K \oplus X$. This means that $K$ and $X$ are mutual supplements in $N$. Thus $M$ has the property $(\mathrm{ME})$.

$(2) \Longrightarrow(1)$ is trivial.

Let $R$ be a ring and $M$ be a left $R$-module. Take two sets $I$ and $J$, and for every $i \in I$ and $j \in J$, an element $r_{i_{j}}$ of $R$ such that, for every $i \in I$, only finitely many $r_{i_{j}}$ are non-zero. Furthermore, take an element $m_{i}$ of $M$ for every $i \in I$. These data describe a system of linear equations in $M$ :

$$
\sum_{j \in J} r_{i_{j}} x_{j}=m_{i} \text { for every } i \in I \text {. }
$$


The goal is to decide whether this system has a solution, i.e. whether there exist elements $x_{j}$ of $M$ for every $j \in J$ such that all the equations of the system are simultaneously satisfied (note that we do not require that only finitely many of the $x_{j}$ are non-zero here). Now consider such a system of linear equations, and assume that any subsystem consisting of only finitely many equations is solvable (the solutions to the various subsystems may be different). If every such "finitely-solvable" system is itself solvable, then the module $M$ is called algebraically compact. For example, every injective module is algebraically compact.

Corollary 1. Let $R$ be a commutative Noetherian ring. Then, the following three statements are equivalent for a semisimple left $R$-module $M$.

(1) $M$ has the property (ME).

(2) $M$ is algebraically compact.

(3) Almost all isotopic components of $M$ are zero.

Proof. It follows from Proposition 1 and [10, Proposition 1.6].

It is clear that every injective module has the property (ME), but the following example shows that a module with the property (ME) need not be injective. Firstly, we need the following crucial lemma.

Lemma 1. Every simple module has the property $(M E)$.

Proof. Let $M$ be a simple module and $N$ be any extension of $M$. Since $M$ is simple, then $M \ll N$ or $M \oplus K=N$ for a submodule $K$ of $N$. In the first case, $N$ is a supplement of $M$ in $N$ such that $N$ and 0 are mutual supplements in $N$. In the second case, $K$ is a supplement of $M$ in $N$ such that $K$ and $M$ are mutual supplements in $N$. So, in each case $M$ has the property (ME).

Recall from [2] that a ring $R$ is von Neumann regular if every element $a \in R$ can be written in the form axa, for some $x \in R$. More formally, a ring $R$ is regular in the sense of von Neumann if and only if the following equivalent conditions hold:

(1) $\frac{R}{I}$ is a projective $R$-module for every finitely generated ideal $I$,

(2) every finitely generated left ideal is generated by an idempotent,

(3) every finitely generated left ideal is a direct summand of $R$.

Example 1 ([3, 6.1]). (1) Let $V$ be a countably infinite-dimensional left vector space over a division ring $S$. Let $R=\operatorname{End}\left({ }_{S} V\right)$ be the ring of left linear operators on $V$. Then $R$ is a von Neumann regular ring. Claim that the simple left $R$-module $V$ is not injective. Assume the contrary that ${ }_{R} V$ is injective. Consider a basis $\left\{v_{i} \mid i \in \mathbb{N}\right\}$ of $V$. For each $i \in \mathbb{N}$, let us define $f_{i} \in R$ by $f_{i}\left(v_{i}\right)=v_{i}$ and $f_{i}\left(v_{i}\right)=0$ for $i \neq j$. Set $A=\sum_{i} R f_{i}$. Then $A$ is a left ideal of $R$. Consider a left $R$-homomorphism $\varphi: A \longrightarrow_{R} V$ defined by $\varphi\left(\sum_{i} r_{i} f_{i}\right)=\sum_{i} r_{i} v_{i}$, where $r_{i} \in R$ is zero for all but finitely many $i$. Since ${ }_{R} V$ is injective, there exists $v \in V$ such that $\varphi\left(f_{i}\right)=f_{i} v$ for every $i \in \mathbb{N}$. This gives $v_{i}=f_{i} v$ for every $i \in \mathbb{N}$. Now if $v=d_{1} v_{1}+d_{2} v_{2}+\cdots+d_{n} v_{n}$, then any $i \in \mathbb{N} \backslash\{1,2, \ldots, n\}$, we have $f_{i} v=0$, a contradiction. This shows ${ }_{R} V$ is not injective. Thus $R$ is not a left $V$-ring as the simple left $R$-module $V$ is not injective. By Lemma 1, the left $R$-module $V$ has the property (ME). 
(2) Consider the simple $\mathbb{Z}$-module $\frac{\mathbb{Z}}{p \mathbb{Z}}$, where $p$ is prime. By Lemma 1, M has the property (ME). On the other hand, it is not injective.

Recall from $[9,41.13]$ that an $R$-module $M$ is $\pi$-projective (or co-continious) if for every two submodules $U, V$ of $M$ with $U+V=M$ there exists $f \in \operatorname{End}_{R}(M)$ with $\operatorname{Im}(f) \subset U$ and $\operatorname{Im}(1-f) \subset V$.

Lemma 2. Let $M$ be a module with the property $(M E)$ and $N$ be an extension of $M$ such that $N$ is $\pi$-projective or $\operatorname{Rad}(N)=0$. Then, $M$ is a direct summand of $N$.

Proof. Let $N$ be any extension of $M$. Since $M$ has the property (ME), there exist submodules $K$ and $K^{\prime}$ of $N$ such that $N=M+K, M \cap K \ll K$ and $K, K^{\prime}$ are mutual supplements in $N$. It follows from $[9,41.14(2)]$ that $N=M \oplus K$.

If $\operatorname{Rad}(N)=0$, then $M \cap K \subseteq \operatorname{Rad}(N)=0$. We have $N=M \oplus K$.

A ring $R$ is said to be a left $V$-ring if every simple left $R$-module is injective. It is well known that $R$ is left $V$-ring if and only if $\operatorname{Rad}(M)=0$ for every left $R$-module $M$.

Proposition 2. For a module $M$ over a left $V$-ring $R$, the module $M$ is injective if and only if $M$ has the property $(M E)$.

Proof. $(\Longrightarrow)$ It is clear.

$(\Longleftarrow)$ It follows from Lemma 2 .

Corollary 2. Let $R$ be a commutative von Neumann regular ring. Then, an $R$-module $M$ has the property $(M E)$ if and only if it is injective.

Proof. Since $R$ is a commutative von Neumann regular ring, it is a left $V$-ring. Hence, the proof follows from Proposition 2.

Recall that a ring $R$ is left hereditary if every factor module of an injective left $R$-module is injective [8].

Example 2 ([10]). Let $R=\prod_{i \in I} F_{i}$ be a ring, where each $F_{i}$ is field for an infinite index set I. Then $R$ is a commutative von Neumann regular ring. Since $R$ is not Noetherian, it is not semisimple and so, by the Theorem of Osofsky [6], there is a cyclic R-module (which is clearly a factor module of $R$ ) which is not injective and hence doesn't have the property (ME) by Corollary 2.

Theorem 1. If every free left $R$-module has the property $(M E)$ over a principal ideal domain $R$, then $R$ is left perfect.

Proof. Let $M$ be any free $R$-module. By the hypothesis and [7, Theorem 9.8], every submodule of $M$ has the property (ME). There exist submodules $K$ and $K^{\prime}$ of $M$ such that $M=U+K$, $U \cap K \ll K$, and $K, K^{\prime}$ mutual supplements in $M$ for any submodule $U$ of $M, M=K \oplus K^{\prime}$. So $M$ is $\oplus$-supplemented. It follows from [4, Corollary 2.11] that $R$ is left perfect. 


\section{REFERENCES}

[1] Clark J., Lomp C., Vanaja N., Wisbauer R. Lifting Modules. Supplements and Projectivity in Module Theory. Frontiers in Mathematics, Birkhäuser-Basel, 2006. doi:10.1007/3-7643-7573-6

[2] Jacobson N. Basic Algebra II. W. H. Freeman and Company. Yale University, New York, 1989.

[3] Jain S.K., Srivastava A.K., Tuganbaev A.A. Cyclic Modules and The Structure of Rings. Oxford Mathematical Monograps, Oxford Science Publications, 2012.

[4] Keskin D., Smith P.F., Xue W. Rings whose modules are $\oplus$-supplemented. J. Algebra 1999, 218, 470-487.

[5] Mohamed S.H., Müller B.J. Continuous and Discrete Modules. London Math. Soc. Lecture Note Ser. 147, Cambridge University Press, Cambridge, 1990. doi:10.1017/CBO9780511600692

[6] Osofsky B.L. Rings all of whose finitely generated modules are injective. Pacific J. Math. 1964, 14, 645-650.

[7] Rotman J.J. Advanced Modern Algebra. Prentice Hall, 2003.

[8] Sharpe D.W., Vamos P. Injective Modules. Cambridge Uiversity Press, Cambridge, 1972.

[9] Wisbauer R. Foundations of Modules and Rings. Gordon and Breach, 1991.

[10] Zöschinger H. Moduln, die in jeder erweiterung ein komplement haben. Math. Scand. 1974, 35, $267-287$.

Received 06.02.2020

Revised 23.04.2020

Туркмен Б.Н., Туркмен Е. Замітка про узагальнення ін'єктивних модулів // Карпатські матем. публ. — 2020. — Т.12, №2. - С. 499-503.

Як належне узагальнення ін'єктивних модулів у термінах доповнень скажемо, шо модуль $M$ має властивість (ME), якщо як тільки $M \subseteq N$, то $M$ має доповнення $K$ в $N$, де $K$ має взаємне доповнення в $N$. У цьому дослідженні ми отримуємо, що (1) напівпростий $R$-модуль $M$ має властивість (Е) тоді і тільки тоді, коли $M$ має властивість (МЕ); (2) напівпростий лівий $R$-модуль $M$ над комутативним нетеровим кільцем $R$ має властивість (ME) тоді і тільки тоді, коли $M$ алгебраїчно компактний та тоді і тільки тоді, коли майже всі ізотопні компоненти $M$ $\epsilon$ нульовими; (3) модуль $M$ над регулярним кільцем фон Неймана має властивість (МЕ) тоді і тільки тоді, коли він ін'єктивний; (4) основна область ідеалу $R \in$ досконалою зліва, якшо кожен вільний лівий $R$-модуль має властивість (ME)

Ключові слова і фрази: доповнення, взаємне доповнення, модуль з властивістю (МЕ), ліве досконале кільце. 